\title{
Biomedical Applications of Nanobiosensors: the State-of-the-Art
}

\author{
Mahendra Rai, ${ }^{a}$ Aniket Gade, ${ }^{a}$ Swapnil Gaikwad, ${ }^{a}$ Priscyla D. Marcato ${ }^{b}$ and \\ Nelson Durán *,b,c \\ ${ }^{a}$ Department of Biotechnology, Sant Gadge Baba Amravati University, Amravati-444 602, \\ Maharashtra, India \\ ${ }^{b}$ Biological Chemistry Laboratory, Chemistry Institute, Universidade Estadual de Campinas, \\ CP 6154, 13083-970 Campinas-SP, Brazil \\ ${ }^{c}$ Center of Natural and Human Sciences, Universidade Federal do ABC (UFABC), \\ 09210-170 Santo André-SP, Brazil
}

\begin{abstract}
O desenvolvimento de nanobiosensores é um dos avanços mais recentes no campo da nanotecnologia. A investigação sobre nanobiosensores ópticos com dimensões submicrométricas tem aberto novos horizontes para as medições intracelulares. Aproveitando as propriedades únicas dos nanomateriais, nanobiosensores mais rápidos e sensíveis podem ser desenvolvidos. Além de serem sensíveis e rápidos, os estudos de nanobiosensores têm voltado seus esforços para o desenvolvimento de sensores baseados em nanomateriais que são acessíveis, robustos e reprodutíveis. Os nanobiosensores estão equipados com sondas biorreceptoras imobilizadas, por exemplo, anticorpos, substrato de enzima. A excitação por laser é transmitida para o sistema fotométrico na forma de sinal óptico (fluorescência). Os nanobiosessores poderão revolucionar no futuro o diagnóstico de doenças. A presente revisão discute os conceitos básicos, a evolução e as aplicações biomédicas de nanobiosensores.
\end{abstract}

Development of nanobiosensor is one of the most recent advancement in the field of Nanotechnology. Research on optical nanobiosensors with submicron-sized dimensions has opened new horizons for intracellular measurements. Taking advantage of the unique properties of the nanomaterials, faster and sensitive nanobiosensors can be developed. Apart from being sensitive and fast, the studies related to nanobiosensors have geared their efforts towards the development of nanomaterial-based sensors that are affordable, robust and reproducible. The nanobiosensors are equipped with immobilized bioreceptor probes, e.g., antibodies, enzyme substrate. Laser excitation is transmitted to photometric system in the form of optical signal (fluorescence). Nanobiosensors will revolutionize the future of disease diagnosis. The present review discusses the basic concepts, developments and the biomedical applications of nanobiosensors.

Keywords: nanobiosensor, biomedical, nanotechnology, nanoparticles

\section{Introduction}

The terms "nanoscience" or "nanotechnology" are best used for phenomenon associated with structures approximately $1-100 \mathrm{~nm}$ in size where the properties of interest are due to the size of the structure. However, another definition seems more practical and unconstrained by any arbitrary size limitations: "The design, characterization, production, and application of structures, devices and systems by controlled manipulation of size and shape at

*e-mail: duran@iqm.unicamp.br the nanometer scale that produces structures, devices and systems with at least one novel/superior characteristic or property". ${ }^{1}$ There have been renewed interest and activity in the synthesis, characterization and application of metallic nanoparticles as a novel system. Developments in organization of nanoscale structures into predefined super structures ensure that nanotechnology will play crucial role in many key technologies in the present millennium. It is gaining importance in areas such as catalysis, optics, biomedical sciences, mechanics, magnetic and energy science. The silver and certain other noble metal nanoparticles have many important applications in the 
field of biolabelling, ${ }^{2}$ drug delivery system, ${ }^{3-6}$ filters and also antimicrobial drugs, ${ }^{4,7}$ sensors. ${ }^{8}$

Metallic and inorganic nanoparticles at the nanoscale demonstrate novel properties and functions that differ significantly from those reported in the bulk. The small size, larger surface area, improved solubility and multifunctionality of nanoparticles open many new research avenues for scientists. Nanoparticles reveal unique properties in terms of particle aggregation, photoemission, electrical, magnetic, luminescent, heat conductivity and catalytic activity. These properties have recently been applied in different biological studies like disease diagnosis, bio-molecule detection, sample separation, purification and concentration, signal transduction and amplification (sensors). ${ }^{9}$ These nanoparticles further enhance the detection sensitivity of microbial monitoring, degradation and recovery efficiency of chemicals. ${ }^{10,11}$

Metals are essential components in biological environments, participating in functions as diverse as electron transport, maintenance of structural integrity, enzymatic catalysis and neuronal communication. ${ }^{12}$ For biological measurements, it has been known that sensors of the nanosize regime are essential for minimally invasive cellular monitoring. Nanosensors have been prepared by using various metals for many analytes, including calcium, ${ }^{13}$ oxygen,,${ }^{14}$ potassium,,${ }^{15}$ zinc $^{16}$ and magnesium. ${ }^{17}$

The devices that take advantage of the high specificity of biological reactions for detecting target analytes are known as biosensors. It is a combination of a biological recognition element (specific to the target analyte) with a physical transducer that translates the bio-recognition event into a measurable effect, such as an electrical signal, an optical emission or a mechanical motion (Figure 1). Bioreceptors are important components, which provide specificity to biosensor technologies. They allow for binding of the specific analyte of interest to the sensor for the quantification with minimum interference from other factors in complex sampling mixtures.

In 1960s, Clark and Lyons, ${ }^{18}$ Updike and Hicks ${ }^{19}$ developed the first biosensor based on the specific catalytic interaction of the glucose oxidase enzyme with glucose.

A good definition of a biosensor was published by Topa ${ }^{20}$ and by Pathak et al.:21 "A biosensor is a measurement system for the detection of an analyte that combines a biological component with a physicochemical detector, and a nanobiosensor is a biosensor that works on the nano-scale size as described before".

The biosensor components are divided in the biological elements that are the sensitive part and can be tissues, microorganisms, organelles, cell receptors, enzymes, antibodies, nucleic acids, synthetic receptors and organs..$^{22}$

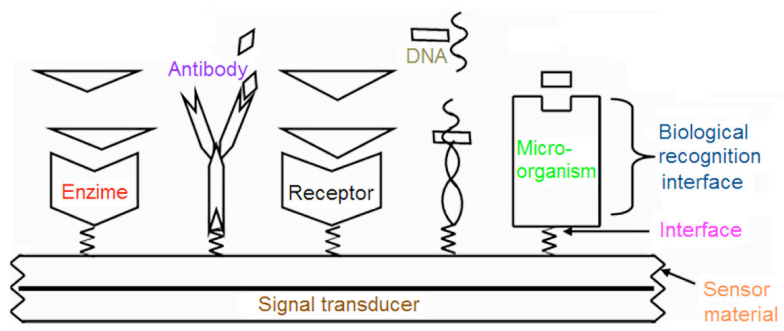

Figure 1. Schematic representation of nanobiosensor components (modified from Topal). ${ }^{20}$

The other important components are the transducer that measures the physical change that occurs with the reaction at the bioreceptor then transforming that energy into measurable electrical output.The latter one is the detector system in which the signals from the transducer are passed to a detector where they are amplified and analyzed and converted to concentration units and transferred to a display or/and data storage device.

The process of detection and amplification is possible to describe as: analyte-bio-receptor-transducer-biocatalystthe output from the transducer is amplified, processed and displayed.

Over the years, new techniques in biosensing have set the stage for great advances in the field of biological research. ${ }^{23-26}$

The quantitative analysis of single components from complex biological and environmental samples has traditionally been achieved by the time-consuming and expensive combination of highly sophisticated chromatographic and spectroscopic techniques. Most recent advances in the field of biosensors include the development of optical nanobiosensors. The development in the nanotechnology leading to the fabrication of optical fibers with submicron-sized dimensions has opened new avenues for intracellular measurements. The application of submicron fiber-optic chemical probes has been developed by Kopelman et al. ${ }^{21-24,27-30}$ who has developed chemical nanoprobes for monitoring $\mathrm{pH}$ and nitric oxide. The use of nanobiosensors for given analytes in medical, ${ }^{31}$ industrial $^{8}$ and environmental ${ }^{32-36}$ applications has meant that alternatives to bulky laboratory-based procedures, especially in the case of in vivo analysis. ${ }^{27,28}$

The photonic explorer for bioanalysis with biologically localized embedding (PEBBLE) scheme has decisive advantages over most means of cellular measurement in terms of the small device size (ca. 20-200 nm spheres) that causes minimal physical perturbation, compared to fibers or electrodes. ${ }^{17,30,37-39}$ The class of devices involves fiber-optic sensors that can be fabricated to have extremely small sizes, making them suitable for monitoring 
intracellular physiological and biological parameters in microenvironments.

\section{State-of-the-Art}

Biosensors, which are devised to integrate a biological probe and a transducer, have been received increasing interest for environmental, industrial and biomedical diagnostics..$^{8,31,35,36}$ The combination of near field scanning optical microscopy (NSOM) and surface-enhanced Raman scattering (SERS) has been used to detect chemicals on solid substrates with sub-wavelength $(100 \mathrm{~nm})$ special resolution. ${ }^{40}$ Nanostructured electrochemical biosensors are prepared by immobilizing the biorecognition elements on the polycarbonate (PC) surrounding gold nanodisks (approximately, $30 \mathrm{~nm}$ in diameter) in nanoelectrode ensembles (NEEs) made in track-etched commercial membranes. A suitable redox mediator is added to the sample solution to shuttle electrons from the nanoelectrodes to the biorecognition layer, both elements being in strict spatial proximity. In this way, one can exploit the highly improved signal-to-background current ratio which is peculiar of NEEs with respect to other electrochemical transducers. Two detection schemes were tested: one based on the direct immobilization of the target protein on the PC of the NEE and other based on the immobilization on PC of an antibody to capture the target protein. In both cases, the biorecognition process was completed by adding a primary antibody and a secondary antibody with horse radish peroxidase (HRP) as enzyme label; methylene blue was the redox mediator added to the electrolyte solution. ${ }^{41}$

Song et al. ${ }^{42}$ reported that the detection of cytochrome $c$ probed in a single cell using the optical nanobiosensor having mouse anticytochrome $c$ antibodies. They proved that the combination of nanobiosensor with the ELISA immunoassay (enzyme-linked immunosorbent assay) improved the detection sensitivity of the nanobiosensor due to enzymatic amplification. Microcantilevers, such as those used in atomic force microscopes, have been recently employed as this new class of biosensors. ${ }^{43}$ Nanomechanical biosensors have demonstrated that they are capable of detecting single base mismatches in oligonucleotide hybridization without labeling, ${ }^{44,45}$ as well as performing protein recognition ${ }^{46}$ with extreme sensitivity. Other DNA detection schemes have been reported, for example, one which is used as a capture oligonucleotide combined with a DNA probe attached to a gold nanoparticle. ${ }^{47}$ This method can detect a single mismatch measured by resonance. Wu et al. ${ }^{48}$ reported the effect of different phosphate buffer concentrations suggesting that electrostatic repulsive forces between neighboring DNA molecules must play a role in cantilever motion and demonstrating that configurational entropy changes and the intermolecular interactions can control the direction of motion in nanomechanical sensors.

The substrate, a three-carbon compound, is immobilized onto gold nanoparticles. The resulting compound is expected to diminish steric hindrances that can hamper the access of the substrate to the active center of the enzyme, thus favoring an improvement in the interaction force. ${ }^{43,49}$ Lechuga et $a l .{ }^{50}$ found that, fabricated devices by standard Silicon CMOS microelectronics technology according to a precise design for achieving a high sensitivity for biosensing applications in genomic and proteomics. They have developed three types of nanobiosensors: $(i)$ a surface plasmon resonance biosensor, (ii) an integrated, Mach-Zehnder nano interferometer device based on optical waveguides and (iii) nanomechanical biosensors based on microcantilevers. Interestingly, the rapid response of enzymatic biosensors based on immobilizing bioactive enzymes and related materials have been attractive and popular field for research. ${ }^{51}$

Nanopore sensor reagent-less electrochemical biosensor was designed, which involves immobilization within Au-coated nanopores of bacterial periplasmic binding proteins (bPBP) for glucose detection. ${ }^{52}$ Some applications of nanosensors, developed for single-cell analysis and applications of biochips for biological sensing of pathogenic agents and medical diagnostics. ${ }^{53,54} \mathrm{~A}$ biochip system constructed for bacteria detection was compact and sensitive. This portable biochip system is expected to contribute significantly to environmental sensing and medical diagnosis. ${ }^{55}$ Current developments in nanoelectronics, biochemistry and information technology are providing feasible development pathways to allow the creation of nanorobots. ${ }^{56-59}$ Nanorobots are considered a new possibility for the health sector to improve medical instrumentation, diagnosis and therapeutic treatments. ${ }^{60}$ Medical nanorobot manufacturing includes embedded and integrated devices, which can comprise the main sensing, actuation, data transmission, remote control uploading and coupling power supply subsystems addressing the basics to biomedical instrumentation. ${ }^{61-65}$

Self-assembling process serves as a powerful tool to generate molecular films of biological molecules on a wide variety of substrates. The ease and simplicity of self assembled monolayers (SAMs) and the ability to control biomolecule surface orientation allow SAMs to play crucial role in the design of artificial biomolecular recognition devices. The SAMs are exploited in many areas of science including biotechnology, material science, microelectronics and superlattices, chemical sensing and molecular recognition, particularly in the future design of 
biosensors.$^{66}$ Biosensor devices, based on the conversion of molecular recognition reactions into useful response signals, offer considerable promise for biological analysis.

\section{Biomedical Applications of Nanobiosensors}

Current developments in nanoelectronics, biochemistry and information technology are providing feasible development pathways to allow the creation of nanorobots. ${ }^{56-58,67,68}$ The design of medical nanorobot will include embedded and integrated devices, which consists of the main sensing, actuation, data transmission, remote control uploading and coupling power supply subsystems. ${ }^{61-64,69,70} \mathrm{~A}$ first series of nanotechnology prototypes for molecular machines is being investigated in different ways, ${ }^{71-74}$ and some interesting devices for propulsion and sensing have been presented. ${ }^{75-78}$ Sensors for biomedical applications are advancing through teleoperated surgery. ${ }^{79-83}$ More complex molecular machines, or nanorobots, having embedded nanoscopic features should provide new tools for common medical treatments. ${ }^{63,84,85}$

\subsection{Detection of diabetes}

Patients with diabetes must take small blood samples many times a day to control glucose levels. Such procedures are extremely uncomfortable and inconvenient. To avoid this problem, the level of sugar in the body can be observed via constant glucose monitoring using medical nanorobotics. To envisage how actual and upcoming stages of nanotechnology can be applied in medicine, numerical analysis and computational nanotechnology, to illustrate the proposed nanorobot performance in the bloodstream, using a 3D vessel as test bed for diabetes control. The nanorobot sensor activation used proteomic-based information to detect biochemical changes associated with hyperglycemia. ${ }^{86}$

The nanorobot exterior consists of carbon metal nanocomposites, which are a diamond-like carbon thin film and possess atomic smoothness, chemical inertness and hardness properties close to those of diamond ${ }^{87}$ It have an artificial glycocalyx surface which minimizes adsorption and bioactivity in relation to fibrinogen as well as other blood proteins, ensuring sufficient biocompatibility to avoid immune system attack. ${ }^{80,81}$ Typically, the favorable characteristics (such as large mobilities and high transconductance) of carbon promote it as an ideal component for integrated nanoelectronics, providing the suitable properties for successful radiofrequency (RF) applications. ${ }^{88-90}$ The nanorobot uses a radiofrequency identification device (RFID) CMOS transponder system for in vivo positioning. ${ }^{91,92}$
The generated information by nanorobots will help doctors and specialists to provide a real-time health care and the medication regimen of the patient. It also reduces the time lost of the patient on suffering from hyperglycemia. A multiplicity of blood-borne nanorobots should allow glucose monitoring from different locations simultaneously throughout the body, thus permitting the physician to assemble a whole-body map of serum glucose concentrations. This will have diagnostic utility in detecting anomalous glucose uptake rates, which can assist in determining the tissues that may have suffered diabetes-related damage, and to what extent. Onboard sensors can also measure and report diagnostically relevant observations such as patient blood pressure, early signs of tissue gangrene or changes in local metabolism related to diabetes. ${ }^{65,86}$ The application of new materials has demonstrated a wide range of possibilities for use in manufacturing better sensors and actuators with nanoscale sizes. ${ }^{77,93}$ These developments along with 3D simulation should assist the design and manufacturing of nanorobots with integrated embedded nanoelectronics and circuits.

Nanorobots should enable a more effective diabetes treatment, helping patients to achieve a healthier and more comfortable life-style. The hardware structural design has provided the greater details on nanorobot safety and durability, with sensing capabilities to monitor diabetes. The nanorobot sensor detection system used proteomicbased information to sense biochemical changes associated with hyperglycemia. The model design, with integrated nanocircuit architecture, deal with major control interface requirements, describing the key parameters for telemetric control and inside-body retrieving information. With reference to integrated architecture, cell phones may play an important role in bringing lives of people into the therapeutic application of medical nanorobotics. ${ }^{94-96}$

\subsection{Immunoassay (detection of $\mathrm{Ab}-\mathrm{Ag}$ reaction)}

It is well well-known that the peak extinction wavelength of the localized surface plasmon resonance (LSPR) spectrum is reliant upon the size, shape and interparticle spacing of the nanoparticles as well as its own dielectric properties and those of its local environment including substrate, solvent and adsorbates..$^{97,98}$ The high sensitivity of the LSPR spectrum of non spherical nanoparticles to adsorbate induced changes in the local dielectric constant (viz., refractive index) are now being used to develop a different class of nanoscale chemosensors and nanobiosensors. This sensor detects changes in the refractive index induced by molecules near the surface of noble metal thin films. ${ }^{99,100}$ 
Riboh et al. ${ }^{101}$ demonstrated LSPR nanobiosensor study on the prototypical immunoassay involving biotin (B) and anti-biotin (AB). The optical biosensors detect change in local refractive index by monitoring the LSPR extinction maximum with UV-Visible spectroscopy.

The maximum LSPR wavelength shift observed for AB binding to biotinylated nanoparticles caused a $+38 \mathrm{~nm}$ red-shift in the LSPR $\lambda_{\max }$. These results indicated that the LSPR nanobiosensor reacts minimally to nonspecific binding, ${ }^{102}$ offering an exciting application of nanoscience to medical diagnostics and biomedical research. ${ }^{103}$ The LSPR nanobiosensor developed in this study expected to demonstrate a wide range of biomedical and environmental applications. The LSPR biosensor may be an alternative to currently existing immunosensors. The sensor designed would be completely noninvasive and capable of organelle specific sensing. LSPR biosensors offer a variety of advantages over traditional flat surface SPR due to the short electromagnetic field decay length $(5-6 \mathrm{~nm})^{101}$ of noble metal nanoparticles. Other kinds of nanobiosensors were also described. ${ }^{104-106}$

\subsection{Application in cancer}

Telomerase is a specialized reverse transcriptase, which is composed of an essential catalytic subunit and an RNA component ${ }^{107,108}$ that, together with telomere-associated proteins, maintains telomere length and function. ${ }^{109,110}$ In normal cells, a critical telomere length is eventually reached, thereby inducing cellular senescence and finally leading to apoptosis. Elevated levels of telomerase activity are found in the majority of malignancies and are believed to play a critical role in tumorgenesis. ${ }^{111-116}$ Telomere dysfunction also results in genetic instability with complex cellular and molecular responses involving the retinoblastoma gene/p53 gene checkpoints and apoptosis pathways. ${ }^{117-119}$

A novel nanobiosensor (based on magnetic nanoparticles) has been developed by Grimm et al. ${ }^{120}$ for rapid screening of telomerase activity in biological samples. ${ }^{121}$ The technique makes use of nanoparticles which, upon annealing to telomerase-synthesized telomeric repeats (TTAGGG), change their magnetic state (a phenomenon readily detectable by magnetic readers). A high throughput version of this technique and the use of magnetic resonance imaging for the purpose of detection allow processing of hundreds of samples within tens of minutes with ultrahigh sensitivities. Nanoparticle assembly formation leads to change in the relaxation time (T2) of surrounding water, which can be readily measured by benchtop magnetic resonance (MR) relaxometers or imaging systems. The developed magnetic nanosensors can be utilized to determine telomerase activity in a variety of applications. The sensitivity of the method ranges from potential single molecule detection (e.g., magnetic force microscopy) to 10-100 attomole levels using Benchtop read-outs (relaxometers). The assay permitted the detection of $c a .10$ attomoles of telomerase-synthesized DNA by MR imaging, which competes well with other PCR (polymerase chain reaction) independent assay methodologies. ${ }^{120}$

Recently, an optical fiber nanobiosensor was constructed to detect efficiently a general cancer biomarker, telomerase at single cell level with its nanoscale tip. ${ }^{122}$

The number of significant advantages shown by developed technique has over other methods are as follows: (i) assay is quantitative, (ii) method is easy and fast (approximately $150 \mathrm{~min}$ for an entire determination and only a minute for actual measurements), (iii) does not requires solid phase, (iv) method can be extended to a highthroughput screening format and $(v)$ achieves high degree of sensitivity without PCR and therefore avoids PCR-related artifacts and difficulties in quantification.

Wang ${ }^{123}$ reported miniaturized devices that enable rapid and direct analysis of the specific binding of small molecules to proteins using silicon nanowire (SiNW) field-effect transistor (FET) devices. Detection of small-molecule inhibitors of long form ATP (adenosine triphosphate) binding to Abl (tyrosine kinase) with constitutive expression that was responsible for chronic myelogenous leukemia. In addition, concentration-dependent inhibition of ATP binding was analyzed for four additional small molecule inhibitors. This study demonstrated that this methodology efficiently distinguishes among the affinities of distinct, small-molecule inhibitors, therefore, useful as platform for drug discovery.

A simple and low cost device to fabricate polySiNW-FET (poly-crystalline silicon nanowire field-effect transistor) for biosensing application was recently published. ${ }^{124}$ Recently, it was also reported a detection method for vascular endothelial growth factor (VEGF) for cancer diagnoses using an anti-VEGF aptamer. ${ }^{125}$

The field of biosensor development for DNA detection can benefit from the advances produced on the synthesis of artificial nucleic acid analogues peptide nucleic acid (PNA) having alluring properties. ${ }^{126}$ PNA is an achiral and uncharged DNA mimic, where the sugar phosphate backbone has been replaced with a peptide like $N$-(2-aminoethyl) glycine polyamide structure, to which the nucleobases are connected by methylene carbonyl linkages.

Standard surface characterization techniques can be employed providing a complement to biochemical analyses due to the small thickness of DNA films $(<10 \mathrm{~nm})$. Thus, recently, the formation of self assembled monolayers 
(SAMs) of thiol-derivatized single stranded forms PNA (ssPNA) chains on gold surfaces has been characterized by surface science techniques, as reflection absorption infrared spectroscopy (RAIRS), X-ray photoelectron spectroscopy (XPS) and atomic force microscopy (AFM). ${ }^{127}$ The molecular orientation of PNAs was strongly dependent on the surface coverage ability. The property of ssPNA to form locally ordered SAMs on gold nanoparticles, which are stabilized by intermolecular interactions of the adjacent nucleotides, provides new challenges for the development of functionalized surfaces with specific recognition properties.

Mateo-Marti et al. ${ }^{128}$ investigated surface science techniques, the potential of Bio-SAMs of PNA to detect specific hybridization of complementary sequences of DNA. They have reported on efficient ssDNA recognition capability of ssPNA molecules on gold surfaces. They used two powerful label-free techniques for surface characterization and DNA detection, synchrotron radiation based X-ray photoemission spectroscopy and polarization modulation RAIRS (PM-RAIRS), presenting a detailed spectroscopic characterization of the process of these techniques. PM-RAIRS are surface specific infrared techniques ideally suited for the study of biomolecule SAMS deposited on a metal surface, RAIRS determines the presence of self-assembled biomolecules on the metal. The technique can also be used to determine the outcome of biomolecular recognition phenomena occurring at SAM surfaces due to its excellent capability for chemical group identification. With the thorough analysis of the $\mathrm{N}$ 1s XPS core-level peak, it is possible to identify each of the chemical components involved in the process and to understand the changes observed in the lineshape of the $\mathrm{N}$ 1s core-level peak due to hybridization of PNA-DNA BioSAMS.

A new methodology by nanostructuring the sensing electrodes creates nucleic acid sensors that have a large sensitivities and that are capable of rapid analysis. This methodology stated that only highly branched electrodes with fine structuring attained molar sensitivity. Planar chips with multiple electrically independent gold leads were passivated with silicon dioxide and at the tip of each lead were apertures with diameters sizes. Using metal electrodeposition under a wide range of plating conditions, it was generated different nanostructured palladium electrodes in the apertures to complete a microelectrode array. The strong binding affinity of palladium for thiols enabled them to functionalize and to attach biomolecular probes on the nanostructured microelectrodes, which were reproducible, robust and programmable. The authors suggested that an intimate link between nanoscale sensor structure and biodetection sensitivity will aid the development of high performance diagnostic tools diseases diagnosis. ${ }^{129}$

Song et al. ${ }^{42}$ demonstrated the intracellular measurement of cytochrome $c$ using an optical nanobiosensor. Cytochrome $c$ is an important protein in the process which produces cellular energy. Moreover, cytochrome $c$ is wellknown as the protein involved in apoptosis, or programmed cell death. $\alpha$-Aminolevulinic acid (5-ALA) was used to induce apoptosis in MCF-7 human breast carcinoma cells. 5-ALA, a photodynamic therapy (PDT) drug in cells was activated by a laser beam (He-Ne). On photoactivation of PDT, the release of cytochrome $c$ from the mitochondria into the cytoplasm of a MCF-7 cell was monitored by the optical nanobiosensor, inserted inside the single cell and also by an enzyme-linked immunosorbent assay (ELISA) outside the cell. $^{69,130}$ The amalgamation of the nanobiosensor with the ELISA immunoassay helped in the improved detection of the nanobiosensor. The above results lead to the investigation of an apoptotic pathway at the single cell level.

Zamuner et al. ${ }^{41}$ has used the polycarbonate capped gold nanodisks $(c a .30 \mathrm{~nm})$ for electrochemical sensors using biorecognition elements in a nanoelectrode ensembles (NEEs) in track-etched commercial membranes. In order to shuttle electrons in the system, a redox mediator was added. They tested two different detection systems, first based on direct immobilization of the protein on polycarbonate of the NEE and second based on the immobilization on polycarbonate of an antibody to interact with the protein. In both cases, primary antibody was added and a secondary antibody with horse radish peroxidase (HRP) as enzyme label; methylene blue was the redox mediator in the electrolyte solution. Typical target analytes as single chain fragment variable protein and transtuzumab (Herceptin) were used in both systems, respectively. These sensors were used on a receptor protein HER2 in biological samples. A novel amperometric immunosensor for determination of human serum chorionic gonadotrophin (hCG) was constructed by Yanga et al. ${ }^{131}$ by immobilizing hCG antibody with nano-gold and chitosan (CHIT) hybrid film electrochemically co-deposited on a glassy carbon electrode.

Nagarth et al. ${ }^{132}$ have reported a pioneering and promising method for isolation of circulating tumor cells (CTCs) in peripheral blood from cancer patients using a microfluidic device.

\subsection{Detection of pathogenic bacteria}

Traditionally, the identification of bacteria is based on morphology in culture and biochemical tests. But, these methods are tedious and sometimes all bacteria do not grow in 
culture and therefore, there is a need to develop fast, sensitive and reliable detection method for the bacteria in clinical samples. Kaittanis et al. ${ }^{133}$ has used superparamagnetic iron oxide nanoparticles for identification of Mycobacterium avium spp. paratuberculosis (MAP) through magnetic relaxation. By application of nanosensors direct detection of pathogenic agent can be done. On the other hand, indirect detection is possible through the assessment of the metabolic activity of the pathogen, for example, the monitoring of the consumption rate of nutrients in solution, where nanosensors will be able to assess the metabolic activity of the microbial pathogen. ${ }^{134}$ Moreover, it will also helped to determine whether the pathogen can reproduce in presence of an antibiotic. Nath et al. ${ }^{135}$ have reported a novel gold nanoparticle-based technique for the assessment of bacterial susceptibility via surface plasmon resonance shifts. In 2008, Fu et al. ${ }^{136}$ developed a novel gold/silicon hetero-structured nanorod-based detection method for Salmonella. The dye molecules attached to silicon nanorods produced fluorescence after coming in contact with Salmonella. The method has tremendous potential in biomedical diagnostics.

A recent and excellent review emphasized the application of bioconjugated quantum dots for the detection of food contaminants such as pathogenic bacterial toxins like botulinum toxin, enterotoxins produced by Staphylococcus aureus, Escherichia coli. ${ }^{137}$

\section{Conclusions}

Nanobiosensors have been emerging with fast pace in the field of biomedical, agricultural and environmental sciences ${ }^{138,139}$ and with special emphasis with layer-bylayer films ${ }^{140-142}$ and with the pioneer research of Brolo and co-workers. ${ }^{143}$

The applications in the field of detection of fatal diseases like cancer and diabetes have brought nanobiosensors in the fore front of research. Rapid assessment of telomerase activity is useful and can be performed by nanobiosensor. A novel nanobiosensor based on magnetic nanoparticles can be utilized for rapid screens of telomerase activity in biological samples. In detection and monitoring of diabetes, traditional methods are often tedious and lack sensitivity. To avoid this problem, the nanorobot sensor can be used since it generates proteomic-based information to detect biochemical changes associated with hyperglycemia. This will also enable more rapid and effective treatment of diabetes. The detection of microbial pathogens and their toxins in patients is now possible by nanobiosensors.

Nanobiosensor can open new avenues towards the development of miniaturized arrays of nanolectrodes, for multi-protein determinations. Nanobiosensor shows the significant improvements in sensitivity, specificity and parallelity in order to meet the future needs of a variety of fields ranging from in vitro medical diagnostics, pharmaceutical discovery and pathogen detection. The use of nanobiosensors in other diseases like tuberculosis, malaria and AIDS will certainly open up new vistas in biomedical research by making the diagnosis quick, accurate, cost-effective and painless. However, the nanobiosensor should be evaluated and approved as medical devices before its marketing.

\section{Acknowledgments}

Fundação de Apoio a Pesquisa do Estado de São Paulo (FAPESP), Conselho Nacional de Desenvolvimento Científico e Tecnológico (CNPq, Binational Project BrazilIndia), DST (India) and INOMAT (CNPq-Brazil) are acknowledged for supporting.

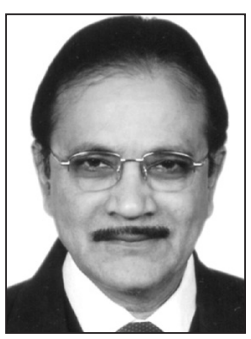

Mahendra Rai is a Professor and Head at the Department of Biotechnology of the Sant Gadge Baba Amravati University (Amravati City, India). He was a Visiting Scientist at the Department of Bioenergetics of the University of Genèva (Genèva City, Switzerland) in 2004 and at the Department of Plant Protection of Debrecen University (Debrecen City, Hungary) in 2005 and 2008. His area of expertise includes microbial biotechnology and nanobiotechnology. His present research interests are nanobiotechnology in medicine and agriculture, in particular the use of metallic nanoparticles as new generation of antimicrobials. He is the Director of Internal Quality Assurance Cell (IQAC) of the Sant Gadge Baba Amaravti University. He has published more than 200 research papers in India and abroad. In addition, he has edited/authored more than 20 books.

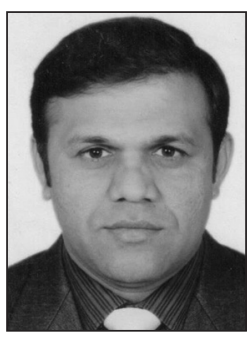

Aniket Gade is an Assistant Professor in the Department of the Biotechnology of Sant Gadge Baba Amravati University (Amravati City, India), where also has submitted his PhD in Biotechnology in 2011, working with mycofabrication of silver nanoparticles by different Phoma sp. and their antimicrobial potential. His interests include mycofabrication of metallic nanoparticles, their functionalization with biomolecules and bioinformatics. 


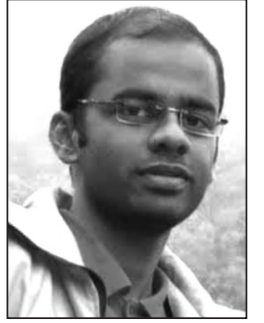

Swapnil C. Gaikwad completed his MSc in 2008 and pursuing the PhD, both degrees in Biotechnology from the Sant Gadge Baba Amravati University (Amravati City (MS), India) under the supervision of Professor Mahendra K. Rai. His area of interest is myconanotechnology. His work is focused on mycosynthesis of silver nanoparticles, characterization and their application as potential antimicrobial agent.

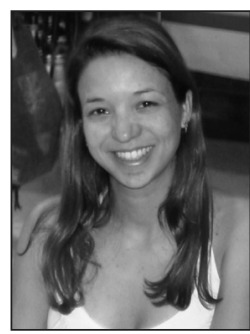

Priscyla D. Marcato received her $P h D$ in Science from the Universidade Estadual de Campinas (UNICAMP, Campinas City, Brazil) in the group of Professor Nelson Durán in 2009, working with nanostructured pharmaceuticals and cosmetics carriers. Her work is focused on the production, characterization and application of biodegradable polymers, solid lipid nanoparticles and biogenic silver nanoparticles.

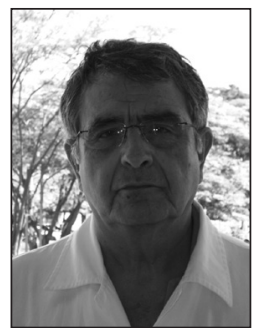

Nelson Durán is a Professor at the Chemistry Institute of the Universidade Estadual de Campinas (UNICAMP, Campinas City, Brazil). He received his $P h D$ at the University of Porto Rico (USA) in the group of Professor W. Adam in 1972, working on photolysis and thermolysis of 1,2-dioxolanes. He was an Associate Professor at the Universidad Catolica de Valparaiso (Valparaiso City, Chile) from 1973 to 1975 and carried out a Visiting Professorship at the Universidade de São Paulo (USP, São Paulo State, Brazil) in 1975, investigating enzymatic generation of excited states intermediates. In 1978, he jointed the Chemistry Institute of the Universidade Estadual de Campinas working in biological chemistry and biotechnology. His present research interests are nanobiotechnology in cosmetics and in pharmaceuticals, besides metallic nanoparticles as antibiotics carriers.

\section{References}

1. Bawa, R.; Bawa, S. R.; Maebius, S. B.; Flynn, T.; Wei, C.; Nanomedicine: NBM 2005, 1, 150.

2. Kulesza, A.; Mitrić, R.; Bonačić-Koutecký, V.; Eur. Phys. J. D 2009, 52, 203.
3. Marcato, P. D.; Durán, N.; J. Nanosci. Nanotechnol. 2008, 8, 2216.

4. Durán, N.; Marcato, P. D.; De Conti, R.; Alves, O. L.; Costa, F. T. M.; Brocchi, M.; J. Braz. Chem. Soc. 2011, 21, 949.

5. Bawaskar, M.; Gaikwad, S.; Ingle, A.; Rathod, D.; Gade, A.; Durán, N.; Marcato, P.D.; Raí, M.; Curr. Nanosci. 2011, 6, 376.

6. Lv, Y.; Liu, H.; Wang, Z.; Liu, S.; Hao, L.; Sang, Y.; Liu, D.; Wang, J.; Boughton, R. I.; J. Membr. Sci. 2009, 331, 50.

7. Rai, M.; Yadav, A.; Gade, A.; Biotechnol. Adv. 2009, 27, 76.

8. Baruah, S.; Dutta, J.; Environ. Chem. Lett. 2009, 7, 191.

9. Jain, K. K.; Clin. Chem. 2007, 53, 2002.

10. Shtykov, S. N.; Rusanova, T. Y.; Russ. J. Gen. Chem. 2008, 78, 2521.

11. Urban, G. A.; Meas. Sci. Technol. 2009, 20, 012001.

12. Kidd, P.; Barceló, J.; Bernal, M. P.; Navari-Izzo, F.; Poschenrieder, C.; Shilev, S.; Clemente, R.; Monterroso, C.; Environ. Exper. Bot. 2009, 67, 243.

13. Asif, M. H; Nur, O.; Willander, M.; Danielsson, B.; Biosens. Bioelectron. 2009, 24, 3379.

14. Henderson, J. R.; Fulton, D. A.; McNeil, C. J.; Manning, P.; Biosens. Bioelectron. 2009, 24, 3608.

15. Oberleithner, H.; Callies, C.; Kusche-Vihrog, K.; Schiller, H.; Shahin, V.; Riethmueller, C.; MacGregor, G. A.; de Wardener, H. E.; Proc. Natl. Acad. Sci. U. S. A. 2009, 106, 2829.

16. Teolato, P.; Rampazzo, E.; Arduini, M.; Mancin, F.; Tecilla, P.; Tonellato, U.; Chem. Eur. J. 2007, 13, 2238.

17. Park, E. J.; Brasuel, M.; Behrend, C.; Philbert, M. A.; Kopelman, R.; Anal. Chem. 2003, 75, 3784.

18. Clark, L.; Lyons, C.; Ann. N. Y. Acad. Sci. 1962, 102, 29.

19. Updike, S. J.; Hicks, G. P.; Nature 1967, 214, 986.

20. Topal, C. O.; Fundamentals of Nanotechnology: From Synthesis to Self-Assembly Course (at Oklahoma State University), 2007, http://frontpage.okstate.edu/nanotech/ Reports/2007/Presentations/Cagri\%20 Ozge\%20Topal. ppt\#256,1,NANOBIOSENSORS, accessed in March 2011.

21. Pathak, P.; Katiyar, V. K.; Giri, S.; J. Nanotechnol. Online. 2007, DOI: $10.2240 /$ azojono0116.

22. Shana, A.; Rogers, K. R.; Meas. Sci. Technol. 1994, 5, 461.

23. Jain, K. K.; Clin. Chem. 2007, 53, 2002.

24. Alfinito, E.; Pennetta, C.; Reggiani, L.; Sens. Actuators, B 2010, 146, 554.

25. Shi, H., Yeh, J. I.; Nanomedicine 2007, 2, 587.

26. Shi, H.; Xia, T.; Nel, A. E.; Yeh, J. I.; Nanomedicine (Philadelphia, PA, U. S.) 2007, 2, 599.

27. Tan, W.; Shi, Z. Y.; Kopelman, R.; Anal. Chem. 1992, 64, 2985.

28. Tan, W.; Shi, Z. Y.; Smith, S.; Birnbaum, D.; Kopelman, R.; Science 1992, 258, 778.

29. Xu, H.; Aylott, J. W.; Kopelman, R.; Miller, T. J.; Philbert, M. A.; Anal. Chem. 2001, 73, 4124.

30. Sumner, J. P.; Aylott, J. W.; Monson, E.; Kopelman, R.; Analyst 2002, 127, 11. 
31. Kerman, K.; Saito, M.; Yamamura, S.; Takamura, Y.; Tamiya, E.; TrAC, Trends Anal. Chem. 2008, 27, 585.

32. Santos, A. S.; Pereira, A. C.; Durán, N.; Kubota, L. T.; Electrochim. Acta 2006, 52, 215.

33. Santos, A. D.; Pereira, A. C.; Sotomayor, M. D. R. T.; Tarley, C. R. T.; Durán, N.; Kubota, L. T.; Electroanalysis 2007, 19, 549.

34. Pereira, A. C.; Kisner, A.; Durán, N.; Kubota, L. T. In Nanostructureed Materials in Electrochemistry; Eftekhari, A, ed.; Wiley-VCH: Weinheim, 2008, p. 243.

35. Bogue, R.; Sensor Rev. 2009, 29, 310.

36. Sadik, O. A.; Zhou, A. L.; Kikandi, S.; Du, N.; Wang, Q.; Varner, K.; J. Environ. Monit. 2009, 11, 1782.

37. Clark, H. A.; Hoyer, M.; Parus, S.; Philbert, M. A.; Kopelman, R.; Mikrochim. Acta 1999, 131, 121.

38. Clark, H. A.; Kopelman, R.; Tjalkens, R.; Philbert, M. A.; Anal. Chem. 1999, 71, 4837.

39. Lee, Y. E. K.; Smith, R.; Kopelman, R.; Annu. Rev. Anal. Chem. $\mathbf{2 0 0 9}, 2,57$.

40. Jiang, Y.; Wang,A.; Ren, B.; Tian,Z. Q.; Langmuir 2008, 24, 12054.

41. Zamuner, M.; Mucelli, S. P.; Tormen, M.; Stanta, G.; Ugo, P.; Eur. J. Nanomed. 2008, 1, 33.

42. Song, J. M.; Kasili, P. M.; Griffin, G. D.; Vo-Dinh, T.; Anal. Chem. 2004, 76, 2591.

43. Ansari, M.; Cho, C.; Sensors 2009, 9, 6046.

44. Lee, C. K.; Radhakrishnan, R.; Chen, C. C.; Li, J.; Thillaigovindan, J.; Balasubramanian, N.; J. Lightw. Technol. 2008, 26, 839 .

45. Zhang, N. H.; Chen, J. Z.; J Biomech. 2009, 42, 1483.

46. Xiang, W.; Lee, C. K.; IEEE J. Sel. Top. Quantum Electr. 2009 , $15,1323$.

47. Kim, J. Y.; Lee, J. S.; Nano Lett. 2009, 12, 4564.

48. Wu, G.; Ji, H.; Hansen, K.; Thundat, T.; Datar, R.; Cote, R.; Hagan, M. F.; Chakraborty, A. K.; Majumdar, A.; Proc. Natl. Acad. Sci. U. S. A. 2001, 98, 1560.

49. Frey, B. L.; Corn, R. M.; Anal. Chem. 1996, 68, 3187.

50. Lechuga, L. M.; Tamayo, J.; Calle, A.; Dominguez, C.; Rev. Mexicana Física 2006, 52, 94

51. Wang, H.; Wang, X.; Zhang, X.; Quin, X.; Zhao, Z.; Miao, Z.; Huang, N.; Chen, Q.; Biosens. Bioelectron. 2009, 25, 142.

52. Tripathi, A.; Wang, J.; Luck, L. A.; Suni, II.; Anal. Chem. 2007, $79,1266$.

53. Vo-Dinh, T.; Brian, M.; Cullum, D.; Stokes, L.; Sens. Actuators, B 2001, 74, 2.

54. Pierstorff, E.; Ho, D.; J. Nanosci. Nanotechnol. 2007, 7, 2949.

55. Song, J. M.; Culha, M.; Kasili, P. M.; Griffin, G. D.; Vo-Dinh, T.; Biosens. Bioelectron. 2005, 20, 2203.

56. Freitas Jr., R. A.; Nanomedicine: Basic Capabilities, vol. 1; Landes Bioscience: Georgetown, Texas, 1999.

57. Appenzeller, J.; Martel, R.; Derycke, V.; Rodasavljevic, M.; Wind, S.; Neumayer, D.; Microelectron. Eng. 2002, 64, 391.
58. Liu, J. Q.; Shimohara, K.; IEEE Trans. Syst. Man Cybern. Part C 2007, 37, 325.

59. Khataee, H. R.; Khataee, A. R.; Digest J. Nanomater. Biostruct. 2009, 4, 613 .

60. Couvreur, P.; Vauthier, C.; Pharm. Res. 2006, 23, 1417.

61. LaVan, D. A.; McGuire, T.; Langer, R.; Nat. Biotechnol. 2003, 21,1184

62. Cuschieri, A.; Surgeon 2005, 3, 125.

63. Leary, S. P.; Liu, C. Y.; Apuzzo, M. L. I.; Neurosurgery 2006, 58,1009 .

64. Hede, S.; Huilgol, N.; J. Cancer Res. Ther. 2006, 2, 182.

65. Cavalcanti, A.; Shirinzadeh, B.; Zhang, M.; Kretly, L. C.; Sensors 2008, 8, 2932.

66. Varatharajan, S.; Berchmans, S.; Yegnaraman, V.; J. Chem. Sci. (Bangalore, India) 2009, 121, 665.

67. Vaughn, J. R.; Over the Horizon: Potential Impact of Emerging Trends in Information and Communication Technology on Disability Policy and Practice; National Council on Disability: Washington (DC), 2006.

68. Lim, T. C.; Ramakrishna, S.; Z. Naturforsch., A.: Phys. Sci. 2006, 61, 402.

69. Shi, H.; Xia, T.; Nel, A. E.; Yeh, J. I.; Nanomedicine 2007, $2,599$.

70. Cavalcanti, A.; Shirinzadeh, B.; Freitas Jr., R. A.; Hogg, T.; Nanotechnology 2008, 19, 015103.

71. Mathieu, J. B.; Martel, S.; Yahia, L.; Soulez, G.; Beaudoin, G.; Biomed. Mater. Eng. 2005, 15, 367.

72. Jiang, H. W.; Wang, S. G.; Xu, W.; Zhang, Z. Z.; He, L.; Jiqiren/Robot (China) 2005, 27, 569.

73. Cavalcanti, A.; Freitas Jr., R. A.; IEEE Trans. Nanobiosci. 2005, 4, 133.

74. Behkam, B.; Sitti, M. J.; Dyn. Syst. Meas. Control Trans. ASME 2006, 128, 36.

75. Li, W. J.; Xi, N.; Fung, W. K.; Wong, T. S.; Encyclopedia Nanosci. Nanotechnol. 2004, 7, 351.

76. Xi, J.; Schmidt, J. J.; Montemagno, C. D.; Nat. Mater. 2005, 4, 180.

77. Villar, I. D.; Matias, I. R.; Arregui, F. J.; Claus, R. O.; IEEE Trans. Nanotechnol. 2005, 4, 187.

78. Ding, B.; Seeman, N. C.; Science 2006, 314, 1583.

79. Reuss, J. L.; Kirchner, R. S.; US pat. 63648342002.

80. Freitas Jr., R. A.; Nanomedicine: NBM. 2005, 1, 2.

81. Freitas Jr., R. A.; Int. J. Surg. 2005, 3,1.

82. Nowlin, W. C.; Guthart, G. S.; Younge, R. G.; Cooper, T. G.; Gerbi, C.; Blumenkranz, S. J.; US pat. 6879882005.

83. Andrews, R. J.; Ann. N. Y. Acad. Sci. 2007, 1122, 169.

84. Patel, G. M.; Patel, G. C.; Patel, R. B.; Patel, J. K.; Patel, M.; J. Drug. Target. 2006, 14, 63.

85. Cavalcanti, A.; Shirinzadeh, B.; Freitas Jr., R. A.; Kretly, L. C.; Recent Pat. Nanotechnol. 2007, 1,1.

86. Cavalcanti, A.; Shirinzadeh, B.; Kretly, L. C.; Nanomedicine 2008, $4,127$. 
87. Narayan, R. J.; Diam. Relat. Mat. 2005, 14, 1319.

88. Musa, G.; Mustata, I.; Ciupina, V.; Vladoiu, R.; Prodan, G.; Vasile, E.; Diam. Relat. Mat. 2004, 13, 1398.

89. Gannon, C. J.; Cherukuri, P.; Yakobson, B. I.; Cognet, L.; Kanzius, J. S.; Kittrell, C.; Cancer 2007, 110, 2654.

90. Rutherglen, C.; Burke, P.; Nano Lett. 2007, 7, 3296.

91. Ricciardi, L.; Pitz, I.; Sarawi, S. F. A.; Varadan, V.; Abbott, D.; Proc. SPIE-Int. Soc. Opt. Eng. 2003, 5119, 199.

92. Ricci, A.; Grisanti, M.; De Munari, I.; Ciampolini, P.; IEEE Trans. Very Large Scale Integrated (VLSI) Systems 2009, 17, 1719.

93. Goicoechea, J.; Zamarreño, C. R.; Matias, I. R.; Arregui, F. J.; Sens. Actuators, B 2007, 126, 41.

94. Gordijo, C. R.; Koulajian, K.; Shuhendler, A. J.; Bonifacio, L. D.; Huang, H. Y.; Chiang, S.; Ozin, G. A.; Giacca, A.; Wu, X. Y.; Adv. Funct. Mater. 2011, 21, 73.

95. Cash, K. J.; Clark, H. A.; Trends Mol. Med. 2010, 16, 584.

96. Samuel, D.; Bharali, D.; Mousa, S. A.; Int. J. Nanotechnol. 2011, 8,53

97. Kreibig, U. In Handbook of Optical Properties, vol. 2; Hummel, R. E.; Wissmann, P., eds.; CRC Press: Boca Raton, 1997, p. 145.

98. Baida, H.; Billaud, P.; Marhaba, S.; Christofilos, D.; Cottancin, E.; Crut, A.; Lerme, J.; Maioli, P.; Pellarin, M.; Broyer, M.; Del Fatti, N.; Vallee, F.; Nano Lett. 2009, 9, 3463.

99. Brockman, J. M.; Nelson, B. P.; Corn, R. M.; Annu. Rev. Phys. Chem. 2000, 51, 41.

100. Huang, C.; Bonroy, K.; Reekman, G.; Verstreken, K.; Lagae, L.; Borghs, G.; Microelectron. Eng. 2009, 86, 2437.

101. Riboh, J. C.; Haes, A. J.; McFarland, A. D.; Yonzon, C. R.; Van Duyne, R. P.; J. Phys. Chem. 2003, 107, 1772.

102. Haes, A. J.; Van Duyne, R. P.; J. Am. Chem. Soc. 2002, 124, 10596.

103. Kim, H. M.; Jin, S. M.; Lee, S. K.; Kim, M. G.; Shin, Y. B.; Sensors 2009, 9, 2334.

104. Choi, J. W.; Oh, B. K.; Kim, Y. K.; Min, H. J.; J. Microbiol. Biotechnol. 2007, 17, 5.

105. Suprun, E.; Bulko, T.; Lisitsa, A.; Gnedenko, O.; Ivanov, A.; Shumyantseva, V.; Archakov, A.; Biosens. Bioelectron. 2010, 25,1694

106. Xiao, G.; Cai, J. Y.; Prog.Chem. 2010, 22, 194.

107. Greider, C. W.; Blackburn, E. H.; Cell 1985, 43, 405.

108. Greider, C. W.; Proc. Natl. Acad. Sci. U. S. A. 1998, 95, 90.

109. Van Steensel, B.; de Lange, T.; Nature 1997, 385, 740.

110. Van Steensel, B.; Smogorzewska, A.; de Lange, T.; Cell 1998, $92,401$.

111. Kim, N. W.; Piatyszek, M. A.; Prowse, K. R.; Harley, C. B.; West, M. D.; Ho, P. L.; Coviello, G. M.; Wright, W. E.; Weinrich, S. L.; Sahy, J. W.; Science 1994, 266, 2011.

112. Shay, J. W.; Bacchetti, S.; Eur. J. Cancer 1997, 33, 787.

113. Bodnar A. G.; Ouellette, M.; Frolkis, M.; Holt, S. E.; Chiu, C. P.; Morin, G. B.; Harley, C. B.; Shay, J. W.; Lichtsteiner, S.; Woodring E.; Wright, W. E.; Science 1998, 279, 349.
114. Counter, C. M.; Meyerson, M.; Eaton, E. N.; Ellisen, L. W.; Caddle, S. D.; Haber, D. A.; Weinberg, R. A.; Oncogene 1998, 16, 1217.

115. Vaziri, H.; Benchimol. S.; Curr. Biol. 1998, 8, 279.

116. Chang, S.; Khoo, C. M.; Naylor, M. L.; Maser, R. S.; DePinho, R. A.; Genes Dev. 2003, 17, 88.

117. Artandi, S. E.; DePinho, R. A.; Curr. Opin. Genet. Dev. 2000, $10,39$.

118. Lan, J.; Xiong, Y. Y.; Lin, Y. X.; Wang, B. C.; Gong, L. L.; Xu, H. S.; World J. Gastroenterol. 2003, 9, 54.

119. Leri, A.; Franco, S.; Zacheo, A.; Barlucchi, L.; Chimenti, S.; Limana, F.; Nadal-Ginard, B.; Kajstura, J.; Anversa, P.; Blasco, M. A.; EMBO J. 2003, 22, 131.

120. Grimm. J.; Perez, M.; Josephson, L.; Weissleder, R.; Cancer Res. 2004, 64, 639.

121. Kaittanis, C.; Santra, S.; Perez, J. M.; J. Amer. Chem. Soc. 2009, 131,12780 .

122. Zheng, X. T.; Li, C. M.; Biosens. Bioelectron. 2010, 25, 1548.

123. Wang, W. U.; Proc. Natl. Acad. Sci. U. S. A. 2005, 102, 3208.

124. Hsiao, C. V.; Lin, C. H.; Hung, C. H.; Su, C. J.; Lo, Y. R.; Lee, C. C.; Lin, H. C.; Ko, F. H.; Huang, T. Y.; Yang, Y. S.; Biosens. Bioelectron. 2009, 24, 1223.

125. Lee, H. S.; Kim, K. S.; Kim, C. J.; Hahn, S. K.; Jo, M. H.; Biosens. Bioelectron. 2009, 24, 1801.

126. Eschenmoser, A.; Chimia 2005, 59, 836.

127. Mateo-Martí, E.; Briones, C.; Roman, E.; Briand, E.; Pradier, C. M.; Martın-Gago, J. A.; Langmuir 2005, 21, 9510.

128. Mateo-Martí, E.; Briones, C.; Pradier, C. M.; Martín-Gago, J. A.; Biosens. Biolectron. 2007, 22, 1926.

129. Soleymani, L.; Fang, Z.; Sargent, E. H.; Shana, O.; Kelley, S. O.; Nature Nanotechnol 2009, 4, 844.

130. Shi, H.; Yeh, J. I.; Nanomedicine 2007, 2, 587.

131. Yang, G. M.; Chang, Y. B.; Yang, H.; Tan, L; Wu, Z. S.; Lu, X. X.; Yang, Y. H.; Anal. Chim. Acta 2009, 644, 72.

132. Nagrath, S.; Sequist, L. V.; Maheswaran, S.; Bell, D. W.; Irimia, D.; Ulkus, L.; Smith, M. R.; Kwak, E. L.; Digumarthy, S.; Muzikansky, A.; Ryan, P.; Balis, U. J.; Tompkins, R. G.; Haber, D. A.; Toner, M.; Nature 2007, 450, 1235.

133. Kaittanis, C.; Naser, S. A.; Perez, J. M.; Nano Lett. 2007, 7, 380.

134. Kaittanis, C.; Nath, S.; Perez, J. M.; PLoS ONE, 2008, 3, e3253, doi:10.1371/journal.pone.0003253.

135. Nath, S.; Kaittanis, C.; Tinkham, A.; Perez, J. M.; Anal. Chem. 2008, 80, 1033.

136. Fu, J.; Park, B.; Siragusa, G.; Jones, L.; Tripp, R.; Zhao, Y.; Cho, Y. J.; Nanotechnology 2008, 19, DOI: 10.1088/09574484/19/15/155502.

137. Vinayaka, A. C.; Thakur, M. S.; Anal. Bioanal. Chem. 2010 , $397,1445$.

138. Vidotti, M.; Carvalhal, R. F.; Mendes, R. K.; Ferreira, D. C. M.; Kubota, L. T.; J. Braz. Chem. Soc. 2011, 22, 3. 
139. Pereira, A. C.; Kisner, A.; Durán, N.; Kubota, L. T.; J. Nanosci. Nanotechnol. 2010, 10, 651.

140. Moraes, M. L.; de Souza, N. C.; Hayasaka, C. O.; Ferreira, M.; Rodrigues Filho, U. P.; Riul Jr., A.; Zucolotto, V.; Oliveira Jr., O. N.; Mat. Sci. Eng. C 2009, 29, 442.

141. Moraes, M. L.; Rodrigues Filho, U. P.; Oliveira Jr., O. N.; Ferreira, M. J.; Solid State Electrochem. 2007, 11, 489.

142. Perinoto, A. C.; Maki, R. M.; Colhone, M. C.; Santos, F. R.; Migliaccio, V.; Daghastanli, K. R.; Stabeli, R. G.; Ciancaglini,
P.; Paulovich, F. V.; de Oliveira, M. C. F.; Oliveira Jr., O. N.; Zucolotto, V.; Anal. Chem. 2010, 82, 9763.

143. Gordon, R.; Sinton, D.; Kavanagh, K. L.; Brolo, A. G.; Acc. Chem. Res. 2008, 41, 1049.

Submitted: May 5, 2011

Published online: October 18, 2011

FAPESP has sponsored the publication of this article. 